This is a post-peer-review, pre-copyedit version of an article published in European Food Research and Technology. The final authenticated version is available online at: https://doi.org/10.1007/ s00217-018-3206-1.

\title{
Chemical evaluation and thermal behavior of Chilean hazelnut oil (Gevuina avellana Mol) a comparative study with virgin extra Olive oil
}

\author{
Marcos Flores García ${ }^{1^{*}}$, Claudia E. Vergara ${ }^{1 *}$, Oscar Forero-Doria ${ }^{2}$, Luis Guzman ${ }^{3}$, \\ Maria Carmen Perez-Camino ${ }^{4}$ \\ ${ }^{1}$ Departamento de Ciencias Básicas, Facultad de Ciencias, Universidad Santo \\ Tomás, Avda. Carlos Schorr 255, Talca, Chile \\ ${ }^{2}$ Instituto de Química de Recursos Naturales, Universidad de Talca, Talca, Maule, \\ Chile \\ ${ }^{3}$ Departamento de Bioquímica Clínica e Inmunohematología, Facultad de Ciencias \\ de la Salud. Universidad de Talca, Talca, Maule, Chile. \\ ${ }^{4}$ Instituto de la Grasa, Sevilla 41013, España.
}

${ }^{*}$ Author to whom correspondence should be addressed

Prof. Dr. Marcos Flores García

Email: marcosflores@santotomas.cl

Tel: +56-71-2342418

Prof. Dr. Claudia Vergara

Email: czvergar@uc.cl

Tel: +56-71-2342418 


\begin{abstract}
There is a growing interest in the study of oils from native fruits, especially when the oil has high quality. In this sense it is mandatory to evaluate the oxidative stability and the relationship with the modifications of the fatty acid content, physicochemical parameters, the antioxidant capacity and its protection against the thermal deterioration processes. The fatty acid profiles of Chilean hazelnut oil showed a relevant presence of the omega series ( $\omega-9, \omega-5$ and $\omega-9)$ with good stability across the thermal treatment. The physics-chemical parameters such as polar compounds and absorption coefficients $\mathrm{K}_{232}$ and $\mathrm{K}_{270}$ shown a similar behavior compared with olive oil oxidation in the range of 25 to $360^{\circ} \mathrm{C}$. The antioxidant capacity and total phenolic content in olive oil is significatively higher than Chilean hazelnut oil at $25^{\circ} \mathrm{C}$, however this antioxidant capacity decreases in the olive oil after $100^{\circ} \mathrm{C}$ until $247^{\circ} \mathrm{C}$ where the antioxidant capacities for both oils are equalized. Total phenolic content of olive oil diminish after $100^{\circ} \mathrm{C}$ until the final study temperature $\left(360^{\circ} \mathrm{C}\right)$ where its concentration is very similar than Chilean hazelnut oil. The results of the thermogravimetric and differential analysis in the range of $100-700^{\circ} \mathrm{C}$ shown that the thermal oxidative decomposition processes occurred in both samples mainly in three steps with a total mass loss for olive oil and Chilean hazelnut oil of 99.7 and $99.9 \%$ respectively. It is important to note that hazelnut oil remains thermally stable up to $247^{\circ} \mathrm{C}$ just a few degrees lower than olive oil $\left(252^{\circ} \mathrm{C}\right)$.
\end{abstract}




\section{Introduction}

Chilean hazelnut (Gevuina avellana $\mathrm{Mol}$ ) is a native variety that grows mainly in the southern part of Chile and Argentina, is characterized by its high-oil content, around $50 \%$ [1]. Chilean Hazelnuts is high content in A and $E$ vitamins, extracts from the hulls of hazelnuts showed high antioxidant activity and offered a great potential as a natural source of carotenoids for using in food technology [2].

The hazelnut oil can be extracted mainly by two methods: by pressing or solvent extraction. The solvent extraction is the most efficient method, however can change the properties of the oil obtained, in addition, presents an environmental risk due to the toxicology of the solvents used. Mechanical pressing oil extraction generally have better preserved native properties and is free of chemical substances being advantageous over the extraction solvent method, but the yield is very low between $10-12 \%$ of oil, wich make it unefficient method to industrial purpose [3,4].

The hazelnut oil has excellent cosmetic properties, because filtering the infrared and UV low spectrum radiation, which gives it application as a solar protection agent and skin regenerator. The oil is composed mainly of unsaturated fatty acids, which represent $93 \%$ of the total [5]. Its main components are oleic and palmitoleic acids, which represent $70 \%$ fatty acids and penetrates into skin faster than other fatty acids, being rapidly adsorbed [6]. This property has allowed its use as a carrier for pharmaceutical and cosmetic products. Often it is added to creams as solar UV filter $[7,8]$.

The unsaturated fatty acid content of the hazelnut oil make it more susceptible to auto-oxidation process. On the other hand, phenolic compounds such as tocopherols and tocotrienols are very important in the antioxidant activity of oils [9] and contribute to their oxidative stability $[9,10]$. The antioxidant activity of tocopherols was reported to be in the order $\alpha>\beta>y>\delta$ under low to mild temperatures and in the reverse order at higher temperatures [11]. Processes at 
high temperature the loss of tocopherols generally becomes more rapid as the degree of oil unsaturation decreases [12].

It has been reported that $\alpha$-tocotrienol was the main natural antioxidant present in this oil $[6,9]$. Also, the addition of $\alpha$-tocopherol and $\alpha$-tocotrienol improved the thermal stability and reduced the formation of polar compounds during thermal oxidation of hazelnut oil [9]. Similarly, it has been shown that the carotenoidtocopherol interaction, through the addition of rosa mosqueta extract on Chilean hazelnut oil, can protect tocols against degradation at high temperature [13].

In processes that occur at high temperatures it is of primary interest to know the changes that suffer the compounds present in the oil to define their relationship with oil deterioration. There is a lack of information in the literature on the behavior of Chilean hazelnut oil at high temperatures and its chemical quality. This deepening in the changes suffered by this oil would be a contribution to knowledge if its behavior is compared with the widely studied extra virgin olive oil.

The principal aim of this research was to investigate the behavior of Chilean hazelnut oil at high temperature conditions and compare with the extra virgin olive oil behavior, through the analysis of antioxidant capacity, total polar compounds, spectrophotometric measurements, fatty acids profile and thermogravimetric analysis.

\section{Experimental}

\section{Chemical and reagents}

Methanol and hexane and other solvents were obtained from Arquimed (Santiago, Chile). Gallic acid, Folin-Ciocalteu, and 2,2-Diphenyl-1-picrylhydrazyl (DPPH) were purchased from Sigma-Aldrich (St. Louis, MO, U.S.A). Other chemicals (analytical grade) used in this study were purchased from Merck (Santiago Chile), unless stated other wise.

\section{Vegetable oils}


The Chilean hazelnuts were collected from the Nahuelbuta mountain in Chile, the hazelnut oil was obtained by pressure according to previously published conditions with some modifications [3]. Approximately $50 \mathrm{~g}$ of ripe Chilean hazelnut were added in a mechanical press (Carver, Inc., Wabash, Indiana, USA), then the crude oil was filtered with filter paper (watman $n^{\circ} 1$ ) and finally the crude oil was centrifuged at $3500 \mathrm{rpm}$ for $20 \mathrm{~min}$ (DLAB, DM04125) to eliminate any residual particles. The hazelnut oil was stored at $5{ }^{\circ} \mathrm{C}$ until analysis. Extra virgin Olive Oil was obtained from the local market.

\section{Thermal oxidation assays}

The oil samples were studied in a thermogravimetric analyzer (Netzsch, STA 409 PC/PG model), under the following conditions; constant heating ramp of $5^{\circ} \mathrm{Cmin}^{-1}$. The heating range was from room temperature to $700^{\circ} \mathrm{C}$, using air as reactive gas with a mass flow of $100 \mathrm{~mL} \mathrm{~min}{ }^{-1}$. In addition, He gas with a flow of $10 \mathrm{~mL} \mathrm{~min}^{-1}$ was used as protection gas in the electronic balance. the mass used for each sample was around $110 \mathrm{mg}$ which was placed in a ceramic pan. Once the TG / DTG curves were obtained, 5 temperatures were selected to carry out a detailed follow-up of the sample degradation process. The selection criteria for

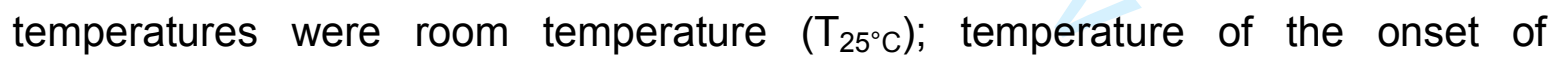

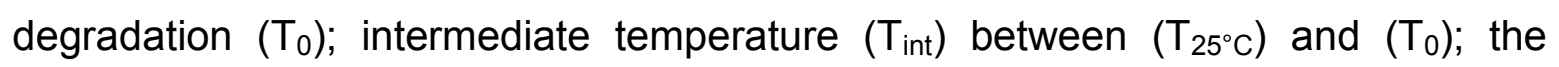
temperature that considers $5 \%$ of the degradation $\left(T_{5 \%}\right)$; the temperature that considers $10 \%$ of the degradation $\left(T_{10 \%}\right)$. 


\section{Fatty acid composition}

Fatty acids were determined in the oils by gas chromatography FID detection, previous preparation of the fatty acid methyl esters derivatives. A Hewlett Packard model 5890 serie II chromatograph fitted with a FID detection (Hewlett-Packard, Palo Alto, CA, USA) equipped with a split-splitless injector, automatic autosampler, and coupled to a computerized Chroncard system for data acquisition was used. It was fitted with a capillary column SP-2380 capillary column (30 m length, $0.25 \mathrm{~mm}$ i.d., $0.20 \mu \mathrm{m}$ film thickness). The carrier gas was hydrogen at a flow rate of $1 \mathrm{~mL} / \mathrm{min}$. the temperatures of the injector and detector were held at 220, and 250, respectively. The initial oven temperature was $180^{\circ} \mathrm{C}$ and a temperature gradient from 180 to $220^{\circ} \mathrm{C}$ at $3{ }^{\circ} \mathrm{C}$ min $^{-1}$ was applied. The sample size was $1 \mu \mathrm{L}$. Standard fatty acid methyl esters (FAME) from Merck (Merck, Darmstadt, Germany) [14]. The identification of the fatty acids was done by comparison of their retention times with those of standard FAME.

\section{Heating of oils}

At least $10 \mathrm{~mL}$ of each oil was added in $25 \mathrm{~mL}$ beaker and then heated through a hot plate with a thermometer to temperature control. Each oil was submitted to different heating temperatures $\left(T_{25^{\circ} \mathrm{C}}, T_{\text {int }}, T_{0}, T_{5 \%}, T_{10 \%}\right)$ selected from TG/DTG survey for $15 \mathrm{~min}$. The determination of total phenolic content, antioxidant activity, fatty acid profile, extinction coefficients and total polar compounds were performed for each temperature with the purpose of to understand the deterioration process applied for the two studied oils.

\section{Total phenolic content (TPC)}

The phenolic content of oil was extracted according to the protocol described by Ali Rehab \& El Anany (2012) with slight modifications [15]. Approximately $5 \mathrm{~g}$ of oil were weighed and placed in a Falcon tube, the oil was combined with an equal 
amount of $\mathrm{n}$-hexane. Then extraction with $5 \mathrm{~mL}$ of a methanol: water mixture (60:40) was performed. The mixture was stirred for $5 \mathrm{~min}$ and then centrifuged at $5500 \mathrm{rpm}$ for $5 \mathrm{~min}$. This procedure was performed at least 3 times. A small portion of hexane was used to wash the aqueous phase and extract oil residues. The TPC of the hydroalcoholic fraction of the oils were determined according to the FolinCiocalteu method [16].

\section{Radical scavenging activity}

Radical scavenging activity (RSA) of the different oil samples was determined as previously described with slight modifications [17]. An aliquot of $75 \mu \mathrm{L}$ of each oil and control ( $80 \%$ methanol), respectively, were combined with $150 \mu \mathrm{L}$ of DPPH. The mixture was shaken vigorously for $10 \mathrm{~s}$ in a screw-capped test tube, and then incubated under dark conditions for $30 \mathrm{~min}$ at room temperature. The spectrophotometric measurements in the solutions were made at a wavelength of $515 \mathrm{~nm}$. The DPPH radical-scavenging activity was calculated using the following formula:

DPPH radical - scavenging activity $(\%)=[(1-A E / A D) \times 100]$, In the formula $A E$ corresponds to the absorbance of the solution after adding the extract of fraction and $A D$ corresponds to the absorbance of the blank DPPH solution. The compound used for quantification was quercetin.

\section{Analysis of polar compounds (PC)}

Testo 270 instrument was used to measure total polar compounds (PC). In accordance with the manufacturer's statement the results are showed in percentage. The sensor is based on parallel plate capacitor, this is immersed in hot oil at about $10 \mathrm{~min}$ after to reach the temperatures obtained from the TG/DTG study. the sensor was immersed at least 1 min until to get stable Reading. Value of TPC was showed in the screen of the monitor. 


\begin{abstract}
Statistical analysis
Results of most the experiment were expressed as mean \pm standard deviation (SD). The statistical analysis ANOVA was used with the software SPSS 18.0 (Statistical Product and Service Solutions). The statistical significance level was set at $p<0.05$.
\end{abstract}

\title{
$\mathrm{K}_{232}$ and $\mathrm{K}_{270}$ Extinction Coefficients
}

Extinction coefficients $\left(\mathrm{K}_{232}\right.$ and $\left.\mathrm{K}_{270}\right)$ of the oil samples were calculated from absorption values measured at 232 and $270 \mathrm{~nm}$. The UV analysis of the oil was performed on a scanning spectrophotometer (Helios Alpha Unicam, using $1 \mathrm{~cm}$ path length quartz cuvettes with hexane as a reference). The calculations were based on the formula, $K_{\lambda}=D_{\lambda} / C$ (eq 1 ), where $K_{\lambda}$ is the specific extinction coefficient for each wavelength, $D_{\lambda}$ is the absorption, and $C$ is the oil concentration in $\mathrm{g} / 100 \mathrm{~mL}[18]$.

\section{RESULTS AND DISCUSSION}

Table $1 \mathrm{~A}$ shows the fatty acid composition of $\mathrm{CHO}$. At the initial temperature of the thermal's study, $\mathrm{CHO}$ is a monounsaturated vegetable oil with a total of $85.16 \%$ of this kind of fatty acids. Represented meanly by oleic acid $(36.8 \%)$ and palmitoleic acid $(23.6 \%)$ with a total of 3 positions's isomers for this last fatty acid. Moreover, $\mathrm{CHO}$ showed a low content of polyunsaturated $(7.95 \%)$ and saturated fatty acids $(6.89 \%)$, represented mostly by linoleic $(7.83 \%)$ and behenic $(2.23 \%)$ fatty acids respectively. The $\mathrm{CHO}$ fatty acid profile is in agreement with data published previously [9]. On the other hand, the higher content of unsaturated fatty acids in $\mathrm{CHO}$ (U/S ratio start at 13.51 until 10.14) sample compare with OO sample (U/S 
initial value $=5.77$ ), would explain a less thermal stability for $\mathrm{CHO}$. It has been reported that there is a relationship between the content of linoleic acid and oxidative stability, where linoleic acid is proposed as the main cause of the chemical rancidification of the hazelnut oil [19]. Additionally, Goncuoglu \& Gokmen (2015) reported range of percentages of fatty acids of 7.65-10.75 for SFA, 89.191.1 for MUFA and 8.2-11.9 PUFA for fourteen Turkish hazelnut varieties harvested in the year 2013 [20]. Being the contribution of fatty acids in decreasing order; oleic acid > linoleic acid > palmitic acid > stearic acid. These total percentages for saturated, monounsaturated and polyunsaturated fatty acids are close to the obtained for Chilean Hazelnut according table 1. However, a different composition in fatty acid could be used for detection of adulterations or a tool to detect authenticity. In the $\mathrm{OO}$ case, see table $1 \mathrm{~B}$, at the initial temperature shows a high percentage of monounsaturated fatty acids represented mainly by oleic fatty acid $(72.43 \%)$. Followed by saturated fatty acids with the palmitic fatty acid $(12.34 \%)$ with the bigger concentration and finally polyunsaturated fatty acids represented mainly by the linoleic fatty acid $(7.57 \%)$. Similar results for fatty acid composition were reported in other countries [21]. U/S ratio for OO is kept in a low range 5.77-4.02 during the thermal's study, suggesting that $O O$ is less sensitive to thermal oxidation than $\mathrm{CHO}$.

Table 1 also shows the changes in fatty acid composition, total saturated fatty acids, total monounsaturated fatty acids and total polyunsaturated fatty acids content in $\mathrm{OO}$ and $\mathrm{CHO}$ during termooxidation study. In general, the results show a change in every fatty acid present in both oils heated from 25 to $360^{\circ} \mathrm{C}$. This range is because over $360^{\circ} \mathrm{C}$ the mass of vegetable oils diminish considerably. There were decreases drastically in polyunsaturated (PUFAs) such as linoleic (C18:2) and linolenic (C18:3) acids including a total disappearance of the last fatty acid in both study oils at the $360^{\circ} \mathrm{C}$. Whereas total saturated fatty acids (SFAs) increased represented mainly by palmitic (C16:0), stearic (C18:0), arachidic (C20:0) and lignoceric acids (C24:0) for both oils. Sulieman et al. (2006) reported that when different vegetable oils are submitted to high temperatures at longer time (16h), the level of polyunsaturated fatty acids such as linoleic acid decreased in contrast to 
saturated fatty acids such as palmitic acid increased [22]. The PUFA / SFA (P/S) ratio is known as the polyene index and is considered as a measure of the degree of polyunsaturation of an oil and its tendency to suffer autoxidation [23]. The difference in fatty acid profile resulted in a polyunsaturated fatty acid/saturated fatty acid $(\mathrm{P} / \mathrm{S})$ ratio from 0.6 to 0.03 for $\mathrm{OO}$ and 1.2 to 0.1 for $\mathrm{CHO}$ at the initial and final study temperatures. It should be noted that $\mathrm{CHO}$ reduce their $\mathrm{P} / \mathrm{S}$ ratio proportionally less than $\mathrm{OO}$ demonstrating that $\mathrm{CHO}$ is stable during deterioration conditions.

In this heating study for both oils total polyunsaturated fatty acids decrease drastically, to less than $0.1 \%$. Total monounsaturated fatty acids increased lightly and total saturated fatty acids increased notoriously, close to $25 \%$ with respect of the initial temperature condition. The behavior of vegetable oils submitted to termooxidation process have been related to degradation firstly to PUFAs, followed by the degradation of MUFAs and finally [24].

In the present study, a very low percentage of geometric isomers (trans fatty acid) for oleic and linoleic acids appeared in the range of temperatures of 247 and $340^{\circ} \mathrm{C}$ respectively in both study oils. Tsuzuki (2010) show that heat induced double bond isomerization by radical species in unsaturated lipid modeling systems [25]. Also, at high temperatures (above $200^{\circ} \mathrm{C}$ ) the double bond can also be shifted to adjacent positions when conjugated systems can be formed [26].

The absorbance $\left(\mathrm{E}_{\mathrm{cm}}{ }^{\%}\right)$ measurements at $232 \mathrm{~nm}\left(\mathrm{~K}_{232}\right)$ and $270 \mathrm{~nm}\left(\mathrm{~K}_{270}\right)$ contribute to the determination of the oxidation of fats. $K_{232}$ has been associated to generation of primary oxidation products (conjugated dienes) and $\mathrm{K}_{270}$ secondary (conjugated trienes) oxidation products. The changes in $\mathrm{E}_{\mathrm{cm}}{ }^{\%}$ at 232 and $270 \mathrm{~nm}$ during heating study for $\mathrm{OO}$ and $\mathrm{CHO}$ are shown in fig. $1 \mathrm{~A}$ and $1 \mathrm{~B}$ respectively. The $E_{c m}{ }^{\%}$ at 232 and 270 for all samples increased with increasing of the temperature, except for the final temperature $\left(360^{\circ} \mathrm{C}\right)$ for $\mathrm{K}_{232}$ case in both samples. It can be observed that from room temperature until $180^{\circ} \mathrm{C}$ the slope of the curve of $K_{232}$ and $K_{270}$ are low compared with the slopes over $180^{\circ} \mathrm{C}$. This situation can be related with the loss of protective compounds to oil oxidation process such as phenolic compounds due boiling point is close to this temperature. 
The levels of conjugated dienes throughout heating time are lower in $\mathrm{OO}$ than $\mathrm{CHO}$ except for the final temperature. Similar behavior was observed for all temperatures for $\mathrm{K}_{270}$ on $\mathrm{OO}$ and $\mathrm{CHO}$. Indicating less stability oxidative for $\mathrm{CHO}$ compared with $\mathrm{OO}$. This situation can be correlated with a higher proportion of monounsaturated fatty acids in $\mathrm{CHO}$ than $\mathrm{OO}$, and it's also complemented with higher content of saturated fatty acid in $\mathrm{OO}$ against $\mathrm{CHO}$. These could be the reasons why $\mathrm{CHO}$ accumulated more conjugated dienes and trienes during all study temperatures.

Whereas the maximum permitted value of $\mathrm{K}_{232}$ and $\mathrm{K}_{270}$ for extra virgin olive oil (EVOO) in the European regulation limits are 2.5 and 0.2 , respectively, in our case $\mathrm{OO}$ at $25^{\circ} \mathrm{C}$ is below these values [27]. The $\mathrm{OO}$ exceed these limits over $180^{\circ} \mathrm{C}$ y $100^{\circ} \mathrm{C}$ for $\mathrm{K}_{232}$ y $\mathrm{K}_{270}$ respectively. For $\mathrm{CHO}$ there are no regulations.

The peroxides index is one of the parameters most used at the industrial level when it is required to measure the deterioration of fats and oils, however this indicator is not very robust because the peroxides are unstable at high temperatures. Some countries propose in their regulations to use the index of polar compounds $(P C)$ to measure the quality of fats subjected to high temperatures, this index is widely used, since it considers the oxidative and hydrolytic deterioration suffered by fat [28]. In the case of our country, the permitted limit is $25 \%$ for oils subjected to frying processes, where a higher value is recommended to discard fat [29]. The Testo 270 measurements are based on changes in the dielectric constant of the heated oil and this measurement has been correlated highly with PC opencolumn conventional method [30]. In this study, the content of PC increased strongly starting from $180^{\circ} \mathrm{C}$ in both vegetable oil, see fig. 2 . In spite of the $P C$ of $\mathrm{CHO}$ were significantly higher than $\mathrm{OO}$ in every study temperature. $\mathrm{PC}$ were less than $25 \%$ at least until $250^{\circ} \mathrm{C}$ for both oils, confirming that $\mathrm{CHO}$ is stable to high temperatures and good alternative to cooking process.

The thermogravimetric analysis was performed in a range from 100 to 700 ${ }^{\circ} \mathrm{C}$, this wide range allows to study the oils from food cooking temperatures (100 $\left.{ }^{\circ} \mathrm{C}\right)$, through frying temperatures $\left(180^{\circ} \mathrm{C}\right)$ reaching degradation total of all the components present in the oil. 
Figure 3 shows the mass loss curves (TG) and the mass loss derivative (DTG) for $\mathrm{OO}$ and $\mathrm{CHO}$ in the temperature range previously discussed. A sequential oxidative thermal decomposition process of three stages occurs in both samples, where a total mass loss of $99.7 \%$ for $\mathrm{OO}$ and 99.9 for $\mathrm{CHO}$ occurs. According to figure 3 it is important to point out that the $\mathrm{CHO}$ remains without loss of mass and therefore thermally stable up to $247{ }^{\circ} \mathrm{C}$. On the other hand, the temperature where the mass loss for $\mathrm{OO}$ begins was $252^{\circ} \mathrm{C}$.

The degradation onset temperatures for both oils is close, slightly the $\mathrm{CHO}$ was lower than $\mathrm{OO}$. However, in the analysis of the first stage of thermal decomposition, it is observed that $\mathrm{CHO}$ loses less mass than $\mathrm{OO}, 84.0$ versus $89.7 \%$ of mass loss. in the second decomposition stage, a drastic loss of mass was observed for both samples, with the mass loss for $\mathrm{CHO}$ being greater compared to $\mathrm{OO}, 13.4 \%$ versus $6.1 \%$. The high loss of mass of the first stage in the heating of vegetable oils has been related to the degradation of polyunsaturated fatty acids (PUFA), which have a greater amount of carbon double bonds susceptible to deterioration, and then degraded monounsaturated fatty acids (MUFA) and lately, saturated fatty acids (SFA) [24].

Although the content of SFA, MUFA and PUFA for $\mathrm{CHO}$ and $\mathrm{OO}$ are different, the temperature at the beginning of the degradation is very similar for both oils, however the loss of mass of the first and second stages of decomposition follows a trend alternating for oils. this behavior can be understood because the thermal stability of an oil not only depends on the content of fatty acids, but also due to protective mechanisms against thermooxidation, in this sense the antioxidants that are found in the unsaponifiable fraction play an important role. Tabee et al. (2008) analyzed the thermal stability of vegetable oils with similar MUFA content, demonstrating that the results depended on the amounts of tocopherol and phytosterols present in the oils [31].

Arora et al. (2000) showed that sunflower oils with higher alpha-tocopherol content were more stable than those that did not [32]. Among the main antioxidants that olive oil presents are hydroxytyrosol, tyrosol and its derivatives (secoiridoids). Cheikhousman et al. (2005) showed that these antioxidants decrease drastically 
when the olive oil is submitted to a heating process (180) for a short period of time (10 $\mathrm{min}$ ) [33]. Berasategui et al. (2012) showed a similar thermal behavior between avocado and olive oil, although the former has more than twice as much phytosterols as the latter and this has a greater amount of tocopherols than the former [34]. In the case of hazelnut oil it has been published that it has high levels of vitamin $E$ that protects it from thermal oxidation to a greater extent than olive oil [35].

At the initial temperature, $\mathrm{OO}$ showed $82.6 \%$ higher content of total phenols than $\mathrm{CHO}$, which decrease as the temperature increases. (Fig. 4A).

For $\mathrm{OO}$ at $25^{\circ} \mathrm{C}$, there is a high phenolic content $\left(80.5 \pm 40 \mathrm{mg} \mathrm{GAE} \mathrm{L}^{-1}\right.$ of oil), which remains almost constant up to $100^{\circ} \mathrm{C}$, after this temperature there is a decreasing of $45.16 \%$ from the initial total phenols content upon reaching the frying temperature $\left(180^{\circ} \mathrm{C}\right)$ (Fig. 4A). From this temperature, a constant decline in the phenolic content was observed, until losing $83.11 \%$ of the initial value at $360{ }^{\circ} \mathrm{C}$. On the other hand, $\mathrm{CHO}$ showed a total phenolic concentration of $14 \pm 15 \mathrm{mg} \mathrm{GAE}$ $\mathrm{L}^{-1}$ at $25{ }^{\circ} \mathrm{C}$, which it's almost constant during the entire temperature study, decreasing only $10.7 \%$ at the final temperature $\left(340{ }^{\circ} \mathrm{C}\right)$. in addition, at final temperature the total phenols content for both vegetable oils is very similar.

The difference in composition and polyphenol content between $\mathrm{OO}$ and $\mathrm{CHO}$ is primary due they are fruit that coming from different trees. This study it's a physico-chemical comparison during a thermal study for both oils. In olive oil highlights the presence of oleuropein, pinoresinol, tyrosol (b.p. $158^{\circ} \mathrm{C}$ ), ferulic acid and hydroxytyrosol (b.p. $174^{\circ} \mathrm{C}$ ) as the most abundant phenolic compounds [36]. Contrarily, the polyphenol content of $\mathrm{CHO}$ derived from the presence of flavonoids over phenolic acids demonstrating the presence of different chemical structure in both oils [2]. Is important to note that the concentration of the total phenolic compounds found in $\mathrm{CHO}$ was much lower than $\mathrm{OO}$; in addition, the major compounds present in $\mathrm{OO}$ are not present in $\mathrm{CHO}$.

$\mathrm{OO}$ has an antioxidant capacity $43.16 \%$ higher than $\mathrm{CHO}$ at $25^{\circ} \mathrm{C}$, this capacity decreases to $247^{\circ} \mathrm{C}$ where the antioxidant capacities for both oils are equalized. This situation is correlated by one hand with a greater amount of total 
phenolic compounds present in $\mathrm{OO}$ than $\mathrm{CHO}$ at the initial temperature and also a similar content in these kind of compounds at final temperatures (Fig. 4B).

It is known that $\mathrm{OO}$ is low concentration in tocopherols. However, these compounds together to phenolic compounds contribute to the oxidative stability of oils [10]. Additionally, $\mathrm{CHO}$ present high amounts of tocotrienols, contributing to improve thermal oxidative stability and also this is a big difference compared other well-known nut oils [37].

\section{Conclusions}

This study shows that hazelnut oil is a good alternative for thermal processes. Chilean hazelnut oil showed a high degree of unsaturation represented mainly by oleic and palmitoleic fatty acids, 36 and $23 \%$ respectively. The follow-up of the change in fatty acid composition indicates a decrease in the indices P/S (polyunsaturated fatty acids / saturated fatty acids) and the U/S index (total unsaturated fatty acids / saturated fatty acids) for both oils. The ratio P/S and U/S for $\mathrm{CHO}$ remained close to twice that of $\mathrm{OO}$ in the temperature range studied. The thermogravimetric study (TG / DTG curves) shows that the degradation of both oils studied is carried out in a three-stage process in the temperature range studied. Hazelnut oil has a high temperature of resistance to mass loss, just $3^{\circ} \mathrm{C}$ below olive oil. Although the content of total phenols in hazelnut oil is much lower than that presented by olive oil at each temperature studied, the antioxidant capacity of both oils is similar from $247^{\circ} \mathrm{C}$. in this sense it is demonstrated that this oil has a good behavior in thermal processes at high temperature.

\section{References}


1. Moure A, Franco D, Santamaria RI, Soto $C$, Sineiro J, Domínguez $H$, Zuñiga ME, Nuñez MJ, Chamy R, Lopez-Munguía A, Lema JM (2001) J Am Oil Chem Soc 78:437-440.

2. Moure A, Franco D, Sineiro J, Domínguez H, Núñez MJ, Lema JM (2000) J Agric Food Chem 48:3890-3897.

3. Uquiche E, Jeréz M, Ortíz J (2008) Innov Food Sci Emerg Technol 9:495-500.

4. Moure A, Domínguez H, Zuñiga ME, Soto C, Chamy R (2002) Food Chem 78:179-186.

5. Zuñiga ME, Soto C, Mora A, Chamy R, Lema JM (2003) Process Biochem 39:51-57.

6. Bertoli C, Fay LB, Stancanelli M, Gumy D, Lambelet P (1998) J Am Oil Chem Soc 75:1037-1040.

7. Santamaria RI, Soto C, Zuñiga ME, Chamy R, López-Munguía A (2003) J Am Oil Chem Soc 80:33-36.

8. Franco D, Núñez MJ, Pinelo M, Sineiro J (2006) Eur Food Res Technol 222:443-450.

9. Romero N, Robert P, Masson L, Ortiz J, Pavez J, Garrido C, Foster M, Dobarganes C (2004) J Sci Food Agric 84:943-948.

10. Franco MN, Galeano-Diaz T, Sanchez J, De Miguel C, Martin-Vertedor D (2014) J Oleo Sci 63:115-125.

11. Kamal-Eldín A, Appelqvist L (1996) Lipids 31:671-694. 
12. Kajimoto G, Kanomi Y, Yoshida H, Shibahara A (1991) J Am Oil Chem Soc 40:196-201.

13. Robert P, Romero N, Ortiz j, Masson L, Barrera-Arellano D (2006) J Am Oil Chem Soc 83:691-695.

14. Ourrach I, Rada M, Perez-Camino MC, Benaissa M, Guinda A (2012) Grasas y Aceites 63:355-364.

15. Ali Rehab FM, El Anany AM (2012) Grasas y Aceites 63:455-465.

16. Singleton VL, Joseph A (1965) Am J Enology Vitic 16:144-158.

17. Forero-Doria O, Flores M, Vergara C, Guzman C (2017) J Therm Anal Calorim 130:959-966.

18. Paz-Antolín I, Molero-Meneses M (2000) Grasas y Aceites 51:424-428.

19. Bonvehí JS, Coll FV (1993) Food Chem 48:237-241.

20. Goncuoglu N, Gokmen V (2015) J Food Compost Anal 44:115-121.

21. Borges TH, Pereira JA, Cabrera-Vique C, Lara L, Oliveira AF, Seiquer I (2017) Food Chem 15:454-462.

22. Sulieman AE-RM, El-Makhzangy A, Ramadan MF (2006) J Food Lipids 13:259-276

23. Farhoosh R, Kenari RE, Poorazrang H (2009) J Am Oil Chem Soc 86:71-76. 
24. Santos JCO, Dos Santos IMG, De Souza AG, Prasad S, Dos Santos AV (2002) J Food Sci 67:1393-1398.

25. Tsuzuki W (2010) Chem Phys Lipids 163:741-745.

26. Destaillats F, Angers P (2002) Lipids 37:435-438.

27. Plard J, Le dréau Y, Rébufa C, Dupuy N (2016) Am J Analyt Chem 7:890-907.

28. Sebastian A, Ghazani S, Marangoni A (2014) Food Res Int 64:420-423.

29. Paul S, Mittal GS, Chinnan MS (1997) Crit Rev Food Sci Nutr 37:635-662.

30. Osawa CC, Guaraldo LA, Ferracini H, Mincauscaste F (2012) Food Control 26:525-530.

31. Tabee E, Azadmard-Damirchi S, Jagerstad M, Dutta PC (2008) J Am Oil Chem Soc 85:857-867.

32. Arora A, Byrem TM, Nair MG, Strasburg GM (2000) Arch Biochem Biophys 373:102-109.

33. Cheikhousman R, Zude M, Bouveresse DJR, Leger CL, Rutledge DN, BirlouezAragon I (2005) Anal Bioanal Chem 382:1438-1443.

34. Berasategi I, Barriuso B, Ansorena D, Astiasarán I (2012) Food Chem 132:439446.

35. Ebrahem KS, Richardson D, Tetley R, Mehlenbacher S (1994) Acta Hortic 351:685-692. 
36. Bayram B, Ozcelik B, Scultheiss G, Frank J, Rimbach G (2013) Food Chem 138:1663-1669.

37. Medel F, Núñez R, Medel G, Palma H, Manquian N, Fuentes R (2009) Acta Hortic 845:687-691. 

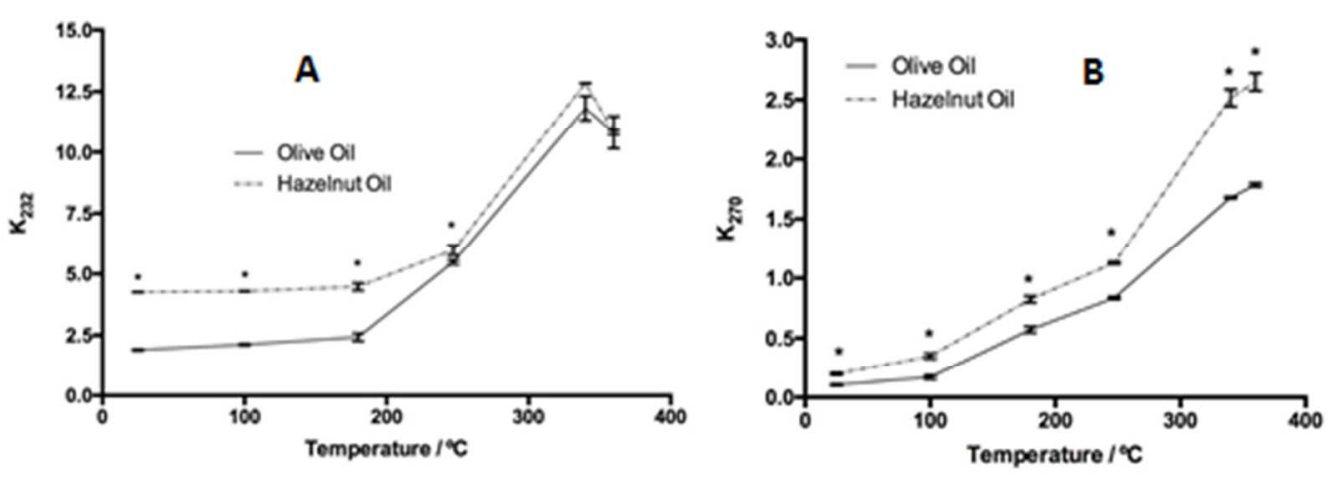

Fig. 1 The absorbance $\left(\mathrm{E}_{\mathrm{cm}}{ }^{\%}\right)$ measurements at $232 \mathrm{~nm}\left(\mathrm{k}_{232}\right)$ for $\mathrm{CHO}$ and OO. ${ }^{*} p$ $<0.05(\mathrm{~A})$ and the absorbance $\left(\mathrm{E}_{\mathrm{cm}}{ }^{\%}\right)$ measurements at $270 \mathrm{~nm}\left(\mathrm{~K}_{270}\right)$ for $\mathrm{CHO}$ and OO. ${ }^{*} p<0.05(\mathrm{~B})$.

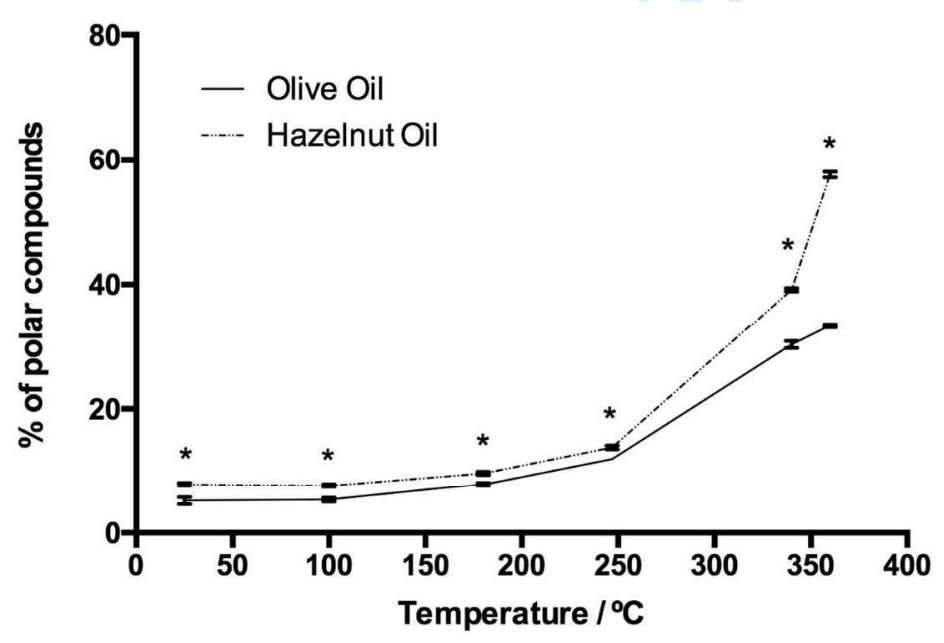

Fig. 2 Measurement of polar compounds in Olive and Hazelnut oils at each studied temperature. ${ }^{*} p<0.05$ 


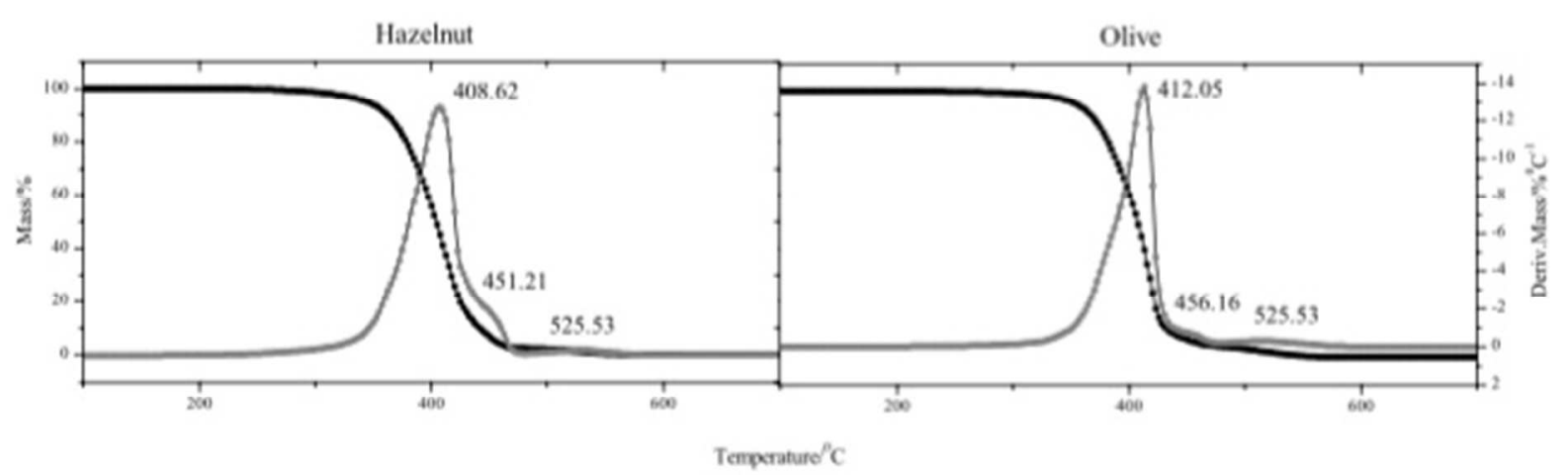

Fig. 3 TG/DTG curves of olive and hazelnut oil.
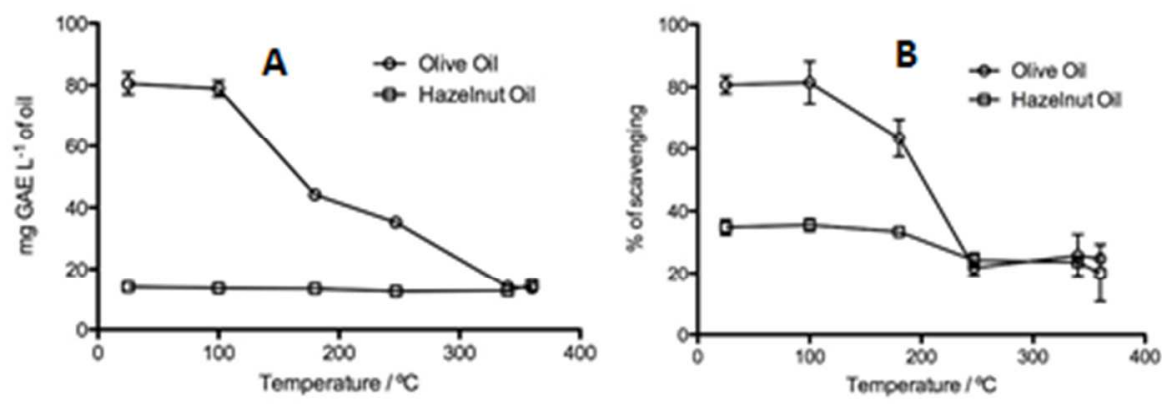

Fig. 4 Total phenolic content of the oils at each studied temperature $(A)$ and antioxidant capacity of the oils at each studied temperature (B). 
Table1A. Changes in fatty acid composition (\%) of Chilean hazelnut oil (CHO) during thermal operation.

\begin{tabular}{|c|c|c|c|c|c|c|}
\hline \multicolumn{7}{|c|}{ Temperatures $\left({ }^{\circ} \mathrm{C}\right)$} \\
\hline Fatty acid ${ }^{*}$ & 25 & 100 & 180 & 247 & 340 & 360 \\
\hline Myristic, C14:0 & 0.05 & 0.05 & - & 0.06 & 0.09 & 0.13 \\
\hline Palmitic,C16:0 & 1.96 & 1.94 & 1.93 & 1.97 & 2.21 & 2.54 \\
\hline Palmitoleic, C16:1,n-9 & 0.12 & 0.12 & 0 & 0.14 & 0.59 & 1.36 \\
\hline Palmitoleic C16:1, n-7 & 0.07 & 0.08 & 0 & 0.07 & 0.1 & - \\
\hline Palmitoleic C16:1,n-5 & 23.36 & 23.32 & 23.02 & 23.27 & 22.79 & 22.75 \\
\hline Margaric, C17:0 & - & - & - & - & - & - \\
\hline Margaroleic, C17:1 & 0.03 & 0.02 & 0.02 & - & - & - \\
\hline Stearic, C18:0 & 0.69 & 0.58 & 0.57 & 0.58 & 0.63 & 0.77 \\
\hline Oleic C18:1,trans & - & - & - & 0.08 & 0.85 & 1.91 \\
\hline Oleic C18:1,n-9 & 36.8 & 36.8 & 36.43 & 36.71 & 36.53 & 36.64 \\
\hline Vaccenic Cis-C18:1, n-7 & 0.55 & 0.53 & 0.56 & 0.54 & 0.55 & 0.68 \\
\hline Vaccenic Cis C18:1 n-5 & 5.85 & 5.86 & 5.76 & 5.84 & 5.69 & 5.63 \\
\hline Linoleic $\square$ C18:2-trans & $\square$ & $\square$ & $\square$ & $\square$ & प०० & प्प० \\
\hline Linoleic C18:2,n-9,n-12 & 7.83 & 7.11 & 7.27 & 6.99 & 4.62 & 0.03 \\
\hline Arachidic, C20:0 & 1.47 & 1.56 & 1.51 & 1.58 & 1.77 & 1.94 \\
\hline Linolenic C18:3-trans & $\square$ & $\square$ & $\square$ & $\square$ & $\square$ & $\square$ \\
\hline Linolenic18:3,ccc,9,12,15 & 0.12 & 0.11 & 0.11 & 0.09 & 0.07 & - \\
\hline Eicosenoic, C20:1 n-9 & 3.07 & 3.11 & 3.01 & 3.12 & 3.29 & 3.6 \\
\hline Eicosenoic, C20:1 n-5 & 6.17 & 6.27 & 6.11 & 6.26 & 6.18 & 6.15 \\
\hline Behenic, C22:0 & 2.23 & 2.36 & 2.27 & 2.39 & 2.65 & 2.93 \\
\hline Docosenoic, C22:1 n-9 & 1.59 & 1.66 & 1.53 & 1.66 & 1.98 & 2.48 \\
\hline Docosenoic, C22:1 n-5 & 7.39 & 7.7 & 7.39 & 7.72 & 7.6 & 7.52 \\
\hline Lignoceric, C24:0 & 0.49 & 0.53 & 0.5 & 0.54 & 0.59 & 0.67 \\
\hline Nervonic, C24:1 n-9 & 0 & 0.05 & 0 & 0.12 & 0.51 & 0.83 \\
\hline Nervonic, C24:1 n-5 & 0.16 & 0.24 & 2.01 & 0.27 & 0.51 & 0.51 \\
\hline Total saturated & 6.89 & 7.02 & 6.78 & 7.12 & 7.94 & 8.98 \\
\hline Total monounsaturated & 85.16 & 85.76 & 85.84 & 85.8 & 87.17 & 90.06 \\
\hline Total polyunsaturated & 7.95 & 7.22 & 7.38 & 7.08 & 4.89 & 0.96 \\
\hline P/S & 1.15 & 1.03 & 1.09 & 0.99 & 0.62 & 0.1 \\
\hline $\mathrm{U} / \mathrm{S}$ & 13.51 & 13.25 & 13.75 & 13.04 & 11.59 & 10.14 \\
\hline
\end{tabular}

${ }^{*}$ As the methyl ester 
Table1B. Changes in fatty acid composition (\%) of olive oil (OO) during thermal operation.

\begin{tabular}{lcccccc}
\hline \multicolumn{7}{c}{ Temperatures $\left({ }^{\circ} \mathrm{C}\right)$} \\
\hline Fatty acid $^{*}$ & $\mathbf{2 5}$ & $\mathbf{1 0 0}$ & $\mathbf{1 8 0}$ & $\mathbf{2 4 7}$ & $\mathbf{3 4 0}$ & $\mathbf{3 6 0}$ \\
Myristic, C14:0 & 0.02 & - & - & - & - & - \\
\hline
\end{tabular}

10

11

12

13

14

15

16

17

18 


\begin{tabular}{|c|c|c|c|c|c|c|}
\hline Palmitic,C16:0 & 12.34 & 12.27 & 12.28 & 12.92 & 15.76 & 17.03 \\
\hline Palmitoleic, C16:1,n-9 & 0.15 & 0.15 & 0.15 & 0.15 & 0.15 & 0.17 \\
\hline Palmitoleic, C16:1, n-7 & 0,77 & 0.77 & 0.78 & 0.79 & 0.85 & 0.92 \\
\hline Palmitoleic, C16:1,n-5 & - & - & - & - & - & - \\
\hline Margaric, C17:0 & 0.08 & 0.08 & 0.08 & 0.08 & 0.15 & 0.15 \\
\hline Margaroleic, C17:1 & 0.17 & 0.17 & 0.17 & 0.17 & 0.19 & 0.23 \\
\hline Stearic, C18:0 & 1.82 & 1.84 & 1.88 & 1.9 & 2.23 & 2.16 \\
\hline Oleic, C18:1,trans & - & - & - & 0.24 & 3.14 & 2.8 \\
\hline Oleic, C18:1,n-9 & 72.43 & 72.2 & 75.57 & 75.33 & 70.99 & 70.25 \\
\hline Vaccenic, Cis-C18:1, n-7 & 3.03 & 3.28 & - & - & 3.38 & 3.25 \\
\hline Vaccenic, Cis C18:1 n-5 & - & - & - & - & - & 0 \\
\hline Linoleic, $\square$ C18:2-trans & $\square$ & $\square$ & $\square$ & $\square$ & 0.32 & प्म० \\
\hline Linoleic, C18:2,n-9,n-12 & 7.67 & 7.69 & 7.5 & 6.94 & 0.3 & 0.23 \\
\hline Arachidic, C20:0 & 0.35 & 0.37 & 0.38 & 0.37 & 0.45 & 0.37 \\
\hline Linolenic, C18:3-trans & $\square$ & $\square$ & $\square$ & $\square$ & $\square$ & $\square$ \\
\hline Linolenic,18:3,ccc,9,12,15 & 0.67 & 0.65 & 0.67 & 0.53 & 0.07 & - \\
\hline Eicosenoic, C20:1 n-9 & 0.33 & 0.35 & 0.35 & 0.34 & 0.37 & 0.31 \\
\hline Eicosenoic, C20:1 n-5 & - & - & - & & - & \\
\hline Behenic, C22:0 & 0.11 & 0.13 & 0.13 & 0.12 & 0.14 & 0.1 \\
\hline Docosenoic, C22:1 n-9 & - & - & - & - & - & - \\
\hline Docosenoic, C22:1 n-5 & - & - & - & - & - & - \\
\hline Lignoceric, C24:0 & 0.06 & 0.05 & 0.06 & 0.12 & 0.08 & 0.1 \\
\hline Nervonic, C24:1 n-9 & - & - & - & - & 1 & 1.16 \\
\hline Nervonic, C24:1 n-5 & - & - & - & - & 0.43 & 0.49 \\
\hline Total saturated & 14.78 & 14.74 & 14.81 & 15.51 & 18.81 & 19.91 \\
\hline Total monounsaturated & 76.88 & 76.92 & 77.02 & 77.02 & 80.5 & 79.58 \\
\hline Total polyunsaturated & 8.34 & 8.34 & 8.17 & 7.47 & 0.69 & 0.51 \\
\hline P/S & 0.56 & 0.56 & 0.55 & 0.48 & 0.04 & 0.03 \\
\hline U/S & 5.77 & 5.78 & 5.75 & 5.45 & 4.31 & 4.02 \\
\hline
\end{tabular}

${ }^{*}$ As the methyl ester 